\title{
Multiplying the Impact of Opioid Settlement Funds by Investing in Primary Prevention
}

\author{
Laura J Faherty, MD, MPH, MS ${ }^{1,2 *}$, Scott E Hadland, MD, MPH, MS ${ }^{3,4}$, \\ Bradley D Stein, MD, PhD 5,6 , Stephen W Patrick, MD, MPH, MS $5,7-10$
}

${ }^{1}$ RAND Corporation, Boston, Massachusetts; ${ }^{2}$ School of Medicine, Boston University, Boston, Massachusetts; ${ }^{3}$ Department of Pediatrics, Boston Medical Center, Boston, Massachusetts; ${ }^{4}$ Division of General Pediatrics, Department of Pediatrics, Boston University, Boston, Massachusetts; ${ }^{5}$ RAND Corporation, Pittsburgh, Pennsylvania; ${ }^{6}$ School of Medicine, University of Pittsburgh, Pittsburgh, Pennsylvania; ${ }^{7}$ Department of Pediatrics, Vanderbilt University, Nashville, Tennessee; ${ }^{8}$ Mildred Stahlman Division of Neonatology, Vanderbilt University, Nashville, Tennessee; ${ }^{9}$ Vanderbilt Center for Child Health Policy, Nashville, Tennessee; ${ }^{10}$ Department of Health Policy, Vanderbilt University, Nashville, Tennessee.

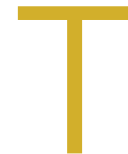

here is growing momentum to hold drug manufacturers accountable for the more than 400,000 US opioid overdose deaths that have occurred since $1999 .{ }^{1}$ As state lawsuits against pharmaceutical manufacturers and distributors wind their way through the legal system, hospitals - which may benefit from settlement funds-have been paying close attention. Recently, former Governor John Kasich (R-Ohio), West Virginia University president E. Gordon Gee, and America's Essential Hospitals argued that adequately compensating hospitals for the costs of being on the crisis' "front lines" requires prioritizing them as settlement fund recipients. ${ }^{2}$

Hospitals should be laying the groundwork for how settlement funds might be used. They may consider enhancing some of the most promising, evidence-based services for individuals with opioid use disorders (OUDs), including improving treatment for commonly associated health conditions such as HIV and hepatitis C virus ( $\mathrm{HCV}$ ); expanding ambulatory longterm antibiotic treatment for endocarditis and other intravenous drug use-associated infections; more broadly adopting harm-reduction practices such as naloxone coprescribing; and applying best practices to caring for substance-exposed infants. They could also develop clinical services not already provided, including creating programs for OUD management during pregnancy and initiating medication for OUD in inpatient, emergency department, and ambulatory settings. In short, hospitals play a critical role in engaging people with OUD in treatment at every possible opportunity. ${ }^{3}$

When considering how to most effectively use opioid settlement funding, hospitals may consider adding or expanding these much-needed clinical services to address opioid-related harms; however, their efforts should not stop there. Investments made outside hospital walls could have a significant effect on the public's health, especially if they target social determinants of health. By tackling factors in the pathway to developing OUD, such as lack of meaningful employment,

*Corresponding Author: Laura J Faherty, MD, MPH, MS; Email: Ifaherty@rand. org; Telephone: 617-338-2059 ×8693; Twitter: @LauraFahertyMD.

Published online first August 19, 2020.

Received: March 20, 2020; Revised: April 22, 2020; Accepted: April 30, 2020

๑ 2020 Society of Hospital Medicine DOI 10.12788/jhm.3455 affordable housing, and mental health care, hospitals can move beyond treating the downstream consequences of addiction and toward preventing community-level opioid-related harms. To accomplish this daunting goal, hospitals will need to strengthen existing relationships with community partners and build new ones. Yet in a 2015 study, only 54\% of nonprofit hospitals proposed a strategy to address the overdose crisis that involved community partnering. ${ }^{4}$

In this Perspective, we describe the following three strategies hospitals can use to multiply the reach of their opioid settlement funding by addressing root causes of opioid use through primary prevention: (1) supporting economic opportunities in their communities, (2) expanding affordable housing options in surrounding neighborhoods, and (3) building capacity in ambulatory practices and pharmacies to prevent OUD (Table).

\section{SUPPORTING ECONOMIC OPPORTUNITY IN THEIR COMMUNITIES}

Lack of economic opportunity is one of many root causes of opioid use. For example, a recent study found that automotive assembly plant closures were associated with increases in opioid overdose mortality. ${ }^{5}$ To tackle this complex issue, hospitals can play a crucial role in expanding employment and career advancement options for members of their local communities. Specifically, hospitals can do the following:

- Create jobs within the healthcare system and preferentially recruit and hire from surrounding neighborhoods

- Establish structured career development programs to build skills among entry-level healthcare employees

- Award contracts of varying sizes to locally owned businesses

- Employ individuals with lived experience with substance use disorders, such as peer recovery coaches ${ }^{6}$

To illustrate how health systems are investing in enhancing career opportunities for members of their communities, hundreds of institutions have implemented "School at Work," a 6-month career development program for entry-level healthcare employees. ${ }^{7}$ The hospitals' Human Resources department trains participants in communication skills, reading and writing, patient safety and satisfaction, medical terminology, and strategies for success and career advancement. Evaluations of this program have demonstrated improved employee outcomes and a favorable return on investment for hospitals. ${ }^{8}$ 
TABLE. How Hospitals Can Invest Opioid Settlement Funds in Primary Prevention

\begin{tabular}{|c|c|}
\hline Strategies & Examples \\
\hline \multirow{2}{*}{$\begin{array}{l}\text { Supporting economic } \\
\text { opportunity }\end{array}$} & - Establish structured career development programs for entry-level healthcare employees \\
\hline & - Employ individuals with lived experience with substance use disorders, particularly as peer recovery coaches \\
\hline Developing affordable housing & - Contribute to supportive housing options \\
\hline \multirow{4}{*}{$\begin{array}{l}\text { Building prevention } \\
\text { capacity }\end{array}$} & - Provide evidence-based training to community providers on safe prescribing practices \\
\hline & - Support ambulatory providers in expanding office-based mental health treatment \\
\hline & - Support ambulatory providers to implement risk reduction strategies to prevent adolescent and young adult initiation of problematic opioid use \\
\hline & - Work with pharmacists to counsel patients on the risks and benefits of prescription opioids \\
\hline
\end{tabular}

As "anchor institutions" and large employers in many communities, hospitals can simultaneously enhance their own workforce and offer employment opportunities that can help break the cycle of addiction that commonly traps individuals and families in communities affected by the overdose crisis.

\section{EXPANDING AFFORDABLE HOUSING OPTIONS}

Hospitals are increasingly supporting interventions that fall outside their traditional purview as they seek to improve population health, such as developing safe green outdoor spaces and increasing access to healthy food options by supporting local farmers markets and grocers. ${ }^{9}$ Stable, decent, and affordable housing is critically important to health and well-being, ${ }^{10}$ and there is a well-documented association of opioid use disorder and opioid misuse with housing instability. ${ }^{11}$ Given evidence of improved outcomes with hospital-led housing interventions, ${ }^{12}$ a growing number of hospitals are partnering with housing authorities and community groups to help do the following ${ }^{13}$ :

- Contribute to supportive housing options

- Provide environmental health assessments, repairs, and renovations

- Buy or develop affordable housing units

Boston Medical Center, where one in four inpatients are experiencing homelessnes and one in three pediatric emergency department patients are housing insecure, provides an example of how a hospital has invested in housing. ${ }^{14}$ In 2017, the hospital began a 5-year, $\$ 6.5$ million investment in community partnerships in surrounding neighborhoods. Instead of building housing units or acting as a landlord, the hospital chose to invest funding in creative ways to increase the pool of affordable housing. It invested $\$ 1$ million to rehabilitate permanent, supportive housing units for individuals with mental health conditions in a nearby Boston neighborhood and in a housing stabilization program for people with complex medical issues including substance use disorder. It provided resources to a homeless shelter near the hospital and to the Boston Health Care for the Homeless Program, which provides healthcare to individuals with housing instability. It also funded a community wellness advocate based at the hospital, who received training in substance use disorders and served as a liaison between the hospital and the Boston Housing Authority.

Housing instability is just one of the social determinants of health that hospitals have the capacity to address as they consider where to invest their opioid settlement funds.

\section{BUILDING PREVENTION CAPACITY IN THE COMMUNITY}

Finally, hospitals can partner with community ambulatory practices and pharmacies to prevent the progression to problematic opioid use and OUD. Specifically, hospitals can do as follows:

- Provide evidence-based training to community providers on safe prescribing practices for acute and chronic pain management, as well as postoperative, postprocedural, and postpartum pain management

- Support ambulatory providers in expanding office-based mental health treatment through direct care via telemedicine and in building mental health treatment capacity through consultation, continuing medical education, and telementorship (eg, Project $\mathrm{ECHO}^{15}$ )

- Support ambulatory providers to implement risk reduction strategies to prevent initiation of problematic opioid use, particularly among adolescents and young adults

- Partner with local pharmacies to promote point-ofprescription counseling on the risks and benefits of opioids Hospitals bring key strengths and resources to these prevention-oriented partnerships. First, they may have resources available for clinical research, implementation support, program evaluation, and quality improvement, bringing such expertise to partnerships with ambulatory practices and pharmacies. They likely have specific expertise among their staff, including areas such as pain management, obstetric care, pediatrics, and adolescent medicine, and can provide specialists for consultation services or telementoring initiatives. They also can organize continuing medical education and can offer in-service training at local practices and pharmacies.

Project $\mathrm{ECHO}$ is one example of telementoring to build capacity among community providers to manage chronic pain 
and address addiction and other related harms. ${ }^{16}$ The Project $\mathrm{ECHO}$ model includes virtual sessions with didactic content and case presentations during which specialists mentor community clinicians. Specific to primary prevention, telementoring has been shown to improve access to evidence-based treatment of chronic pain and mental health conditions, ${ }^{17,18}$ which could prevent the development of OUD. By equipping community clinicians with tools to prevent the development of problematic opioid use, hospitals can help reduce the downstream burden of OUD and its associated morbidity, mortality, and costs.

\section{CONCLUSION}

The opioid crisis has devastated families, reduced life expectancy in certain communities, ${ }^{19}$ and had a substantial financial impact on hospitals_resulting in an estimated \$11 billion in costs to US hospitals each year. ${ }^{20}$ This ongoing crisis is only going to be compounded by the recent emergence of the SARSCoV-2 virus. Hospital resources are being strained in unprecedented ways, which has required unprecedented responses in order to continue to serve their communities. Supporting economic opportunity, stable housing, and mental health treatment will be challenging in this new environment but has never been more urgently needed. If opioid settlement funds are targeted to US hospitals, they should be held accountable for where funds are spent because they have a unique opportunity to focus on primary prevention in their communitiesconfronting OUD before it begins. ${ }^{21}$ However, if hospitals use opioid settlement funding only to continue to provide services already offered, or fail to make bold investments in their communities, this public health crisis will continue to strain the resources of those providing clinical care on the front lines.

\section{Acknowledgment}

The authors wish to thank Hilary Peterson of the RAND Corporation for preparing the paper for submission. She was not compensated for her contribution.

Disclosures: The authors report being supported by grants from the National Institute on Drug Abuse of the National Institutes of Health under awards R21DA045212 (Dr Faherty), K23DA045085 (Dr Hadland), L40DA042434 (Dr Hadland), K23DA038720 (Dr Patrick), R01DA045729 (Dr Patrick), and P50DA046351 (Dr Stein). Dr Hadland also reports grant support from the Thrasher Research Fund and the Academic Pediatric Association. The content of this article is solely the responsibility of the authors and does not necessarily represent the official views of the National Institutes of Health.

\section{References}

1. Scholl L, Seth P, Kariisa M, Wilson N, Baldwin G. Drug and opioid-involved overdose deaths - United States, 2013-2017. MMWR Morb Mortal Wkly Rep. 2018;67(5152):1419-1427. http://doi.org/10.15585/mmwr.mm675152e1

2. Kasich J, Gee EG. Don't forget our frontline caregivers in the opioid epidemic. New York Times. Published September 18, 2019. Accessed December 16, 2019. https://www.nytimes.com/2019/09/17/opinion/opioid-settlement-hospitals.html

3. Englander H, Priest KC, Snyder H, Martin M, Calcaterra S, Gregg J. A call to action: hospitalists' role in addressing substance use disorder. $J$ Hosp Med. 2020;15(3):184-187. https://doi.org/10.12788/jhm.3311

4. Franz B, Cronin CE, Wainwright A, Pagan JA. Measuring efforts of nonprofit hospitals to address opioid abuse after the Affordable Care Act. J Prim Care Communit. 2019;10:2150132719863611. https://doi. org/10.1177/2150132719863611

5. Venkataramani AS, Bair EF, O'Brien RL, Tsai ALC. Association between automotive assembly plant closures and opioid overdose mortality in the United States a difference-in-differences analysis. JAMA Intern Med. 2020;180(2):254-262. https://doi.org/10.1001/jamainternmed.2019.5686

6. Englander H, Gregg J, Gullickson J, et al. Recommendations for integrating peer mentors in hospital-based addiction care. Subst Abus. 2019:1-6. https:// doi.org/10.1080/08897077.2019.1635968

7. Geisinger investing in employees' careers with School at Work program. News Release. Geisinger; November 5, 2018. Updated November 5, 2018. Accessed February 17, 2020. https://www.geisinger.org/about-geisinger/ news-and-media/news-releases/2018/11/19/17/31/geisinger-investing-inemployees-careers-with-school-at-work-program

8. Jackson A, Brasfield-Gorrigan H. Investing in the Future of the Healthcare Workforce: An Analysis of the Business Impact of Select Employee Development Programs at TriHealth in 2013. TriHealth. March 30, 2015. Accessed 20 April 2020. http://www.catalystlearning.com/Portals/O/Documents/TriHealth\%20Rol\%20Study\%20Updated\%20Version.pdf

9. Roy B, Stanojevich J, Stange P, Jiwani N, King R, Koo D. Development of the Community Health Improvement Navigator Database of Interventions. MMWR Suppl. 2016;65:1-9. http://doi.org/10.15585/mmwr.su6502a1

10. Sandel M, Desmond M. Investing in housing for health improves both mission and margin. JAMA. 2017;318(23):2291-2292. https://doi.org/10.1001/ jama.2017.15771

11. Vijayaraghavan M, Penko J, Bangsberg DR, Miaskowski C, Kushel MB. Opioid analgesic misuse in a community-based cohort of HIV-infected indigent adults. JAMA Intern Med. 2013;173(3):235-237. https://doi.org/10.1001/jamainternmed.2013.1576

12. Sadowski LS, Kee RA, VanderWeele TJ, Buchanan D. Effect of a housing and case management program on emergency department visits and hospitalizations among chronically ill homeless adults a randomized trial. JAMA. 2009;301(17):1771-1778. https://doi.org/10.1001/jama.2009.561

13. Health Research \& Educational Trust. Social Determinants of Health Series: Housing and the Role of Hospitals. American Hospital Association. August 2017. Accessed December 16, 2019. https://www.aha.org/ahahretguides/2017-08-22-social-determinants-health-series-housing-and-role-hospitals

14. Boston Medical Center to Invest $\$ 6.5$ Million in Affordable Housing to Improve Community Health and Patient Outcomes, Reduce Medical Costs. Press release. Boston Medical Center; December 7, 2017. Accessed March 4 2020. https://www.bmc.org/news/press-releases/2017/12/07/boston-medical-center-invest-65-million-affordable-housing-improve

15. Arora $S$, Thornton $K$, Murata G, et al. Outcomes of treatment for hepatitis $C$ virus infection by primary care providers. N Engl J Med. 2011;364(23):21992207. https://doi.org/10.1056/nejmoa1009370

16. Chronic Pain and Opioid Management. Project ECHO. Accessed February 16, 2020. https://echo.unm.edu/teleecho-programs/chronic-pain

17. Anderson D, Zlateva I, Davis B, et al. Improving pain care with Project $E C H O$ in community health centers. Pain Med. 2017;18(10):1882-1889. https://doi. org/10.1093/pm/pnx187

18. Frank JW, Carey EP, Fagan KM, et al. Evaluation of a telementoring intervention for pain management in the Veterans Health Administration. Pain Med. 2015;16(6):1090-1100. https://doi.org/10.1111/pme.12715

19. Woolf SH, Schoomaker H. Life expectancy and mortality rates in the United States, 1959-2017. JAMA. 2019;322(20):1996-2016. https://doi.org/10.1001/ jama.2019.16932

20. Opioid Overdoses Costing US Hospitals an Estimated $\$ 11$ Billion Annually. Press Release. Premier; January 3, 2019. Accessed March 4, 2020. https:// www.premierinc.com/newsroom/press-releases/opioid-overdoses-costing-u-s-hospitals-an-estimated-11-billion-annually

21. Butler JC. 2017 ASTHO president's challenge: public health approaches to preventing substance misuse and addiction. J Public Health Manag Pract. 2017;23(5):531-536. https://doi.org/10.1097/phh.0000000000000631 